\title{
New insight into the discrimination between omeprazole enantiomers by cyclodextrins in aqueous solution
}

\author{
A. Figueiras · J. M. G. Sarraguça · A. A. C. C. Pais • \\ J. F. Veiga $\cdot$ R. A. Carvalho
}

Received: 23 January 2008/Accepted: 27 June 2008/Published online: 22 July 2008

(C) Springer Science+Business Media B.V. 2008

\begin{abstract}
We report results regarding the use of ${ }^{1} \mathrm{H}-\mathrm{NMR}$ spectroscopy in the study of the conformational behaviour and optical activity of omeprazole. Changes in the chemical shifts of chosen atoms reveal that the conformational behaviour of omeprazole is temperature and $\mathrm{pH}$ sensitive. Separation and identification of omeprazole enantiomers in the presence of natural and derivative cyclodextrins, such as $\beta$-cyclodextrin $(\beta \mathrm{CD})$ and methyl- $\beta$-cyclodextrin $(\mathrm{M} \beta \mathrm{CD})$ are achieved using ${ }^{1} \mathrm{H}-\mathrm{NMR}$ spectroscopy, with information from molecular dynamics simulation. This work shows that $\beta \mathrm{CD}$ includes preferentially $R$-(-)-omeprazole, acting as a chiral selector. This discrimination of omeprazole enantiomers by cyclodextrins allows development of pharmaceutical formulations with a better bioavailability profile.
\end{abstract}

Keywords Cyclodextrin - Enantiomers ·

Molecular Dynamics · NMR · Omeprazole · Spectroscopy

A. Figueiras · J. F. Veiga

Laboratory of Pharmaceutical Technology, Faculty of Pharmacy,

University of Coimbra, Coimbra, Portugal

J. M. G. Sarraguça · A. A. C. C. Pais

Department of Chemistry, Faculty of Sciences and Technology,

University of Coimbra, Coimbra, Portugal

R. A. Carvalho

NMR Spectroscopy Center, Department of Biochemistry, Faculty of Sciences and Technology, University of Coimbra, Coimbra, Portugal

R. A. Carvalho $(\square)$

Department of Biochemistry, University of Coimbra,

Apartado 3126, 3001-401 Coimbra, Portugal

e-mail: carvalho@ci.uc.pt

\section{Introduction}

Omeprazole is a proton pump inhibitor in gastric parietal cells and has been widely used in the treatment of peptic ulcer, reflux oesophagitis and Zollinger-Ellison syndrome [1]. The molecular structure of omeprazole is composed of a substituted pyridine ring linked to a benzimidazole by a sulphoxide group [2]. Normally, this drug is a racemate with a chiral center in the sulphoxide group (Fig. 1).

It was demonstrated that both enantiomers have the same in vitro capacity to decrease gastric acid formation, but stereoselective metabolism by cytochrome P450 2C19 (abbreviated CYP2C19) results in different plasma concentrations. The $S$-(-)-enantiomer of omeprazole is less susceptible to small intestinal and hepatic metabolism than the $(R)$-isomer, and therefore, the chiral drug achieves between $70 \%$ and $90 \%$ higher steady-state serum concentration than the racemic omeprazole [3].

Cyclodextrins are cyclic organic compounds obtained by enzymatic transformation of starch. These compounds have found many applications because of their ability to form inclusion complexes with a large number of molecules [4-6]. Although their main applications are in pharmaceutical, cosmetic, food and agrochemical industries, cyclodextrins have also proven to be of great utility in analytical chemistry, especially in providing separations of positional and optical isomers [7-9]. One example is the use of cyclodextrins as chiral selectors for separation of omeprazole enantiomers by high performance liquid chromatography in plasma samples and by capillary electrophoresis [10].

The present work reports on the importance of cyclodextrins, namely $\beta \mathrm{CD}$ and $\mathrm{M} \beta \mathrm{CD}$, as chiral selectors and the use of ${ }^{1} \mathrm{H}-\mathrm{NMR}$ spectroscopy and Molecular Dynamics as tools for isomeric selectivity analysis in order to obtain pharmaceutical formulations with better bioavailability. 
(a) ai)

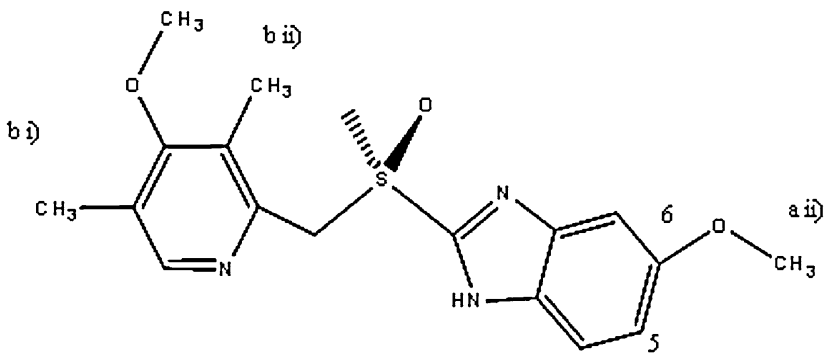

(b)<smiles>COc1ccc2[nH]c([C@@](C)(O)Cc3ncc(C)c(OC)c3C)nc2c1</smiles>

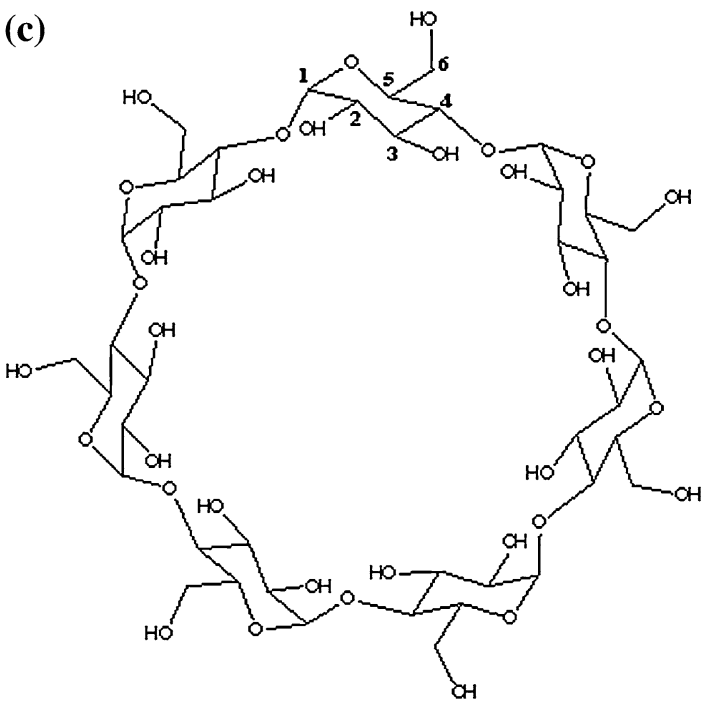

Fig. 1 Chemical structures of omeprazole optical isomers: (a) $R$ and (b) $S$ enantiomers and (c) $\beta$-cyclodextrin

\section{Experimental}

\section{Materials}

Racemic omeprazole (OME) was kindly donated by Belmac Laboratory, S.A. (Madrid, Spain). $\beta$-Cyclodextrin $\left(\beta \mathrm{CD}, \mathrm{M}_{\mathrm{W}}=1135\right)$ and methyl- $\beta$-cyclodextrin $(\mathrm{M} \beta \mathrm{CD}$, $\mathrm{M}_{\mathrm{W}}=1190$ and an average degree of substitution, $\mathrm{DS}=0.5$ ) were kindly donated by Roquette (Lestrem, France). Deuterium oxide $\left(\mathrm{D}_{2} \mathrm{O} ; 99.97 \%\right)$ and $\mathrm{NaOD}$ were purchased from Euriso-top (Peypin, France) and SigmaAldrich (St. Louis, MO), respectively. All other reagents were of the highest purity available from commercial sources.

\section{Methods}

\section{NMR spectroscopy}

${ }^{1} \mathrm{H}-\mathrm{NMR}$ spectra were recorded at $25{ }^{\circ} \mathrm{C}, 35^{\circ} \mathrm{C}$ and $50{ }^{\circ} \mathrm{C}$ on a Varian Unity-500 $\mathrm{MHz}$ spectrometer using a $5 \mathrm{~mm}$ broadband NMR probe and a simple pulse-acquire sequence with solvent presaturation. Acquisition parameters consisted of $24 \mathrm{k}$ points covering a sweep width of $8 \mathrm{kHz}$, a pulse width of $18 \mu \mathrm{s}$, corresponding to a 90 degree rf pulse, and a total repetition time of $15 \mathrm{~s}$. Digital zero filling to $64 \mathrm{k}$ and a $0.5 \mathrm{~Hz}$ exponential were applied before Fourier transformation. The resonance at $4.681 \mathrm{ppm}$ due to residual solvent (HOD) was used as the internal reference. Samples were prepared by dissolving an amount of free and complexed omeprazole with cyclodextrins, previously prepared by the lyophilized method [11], in $\mathrm{D}_{2} \mathrm{O}$ to achieve in an omeprazole concentration of $3 \mathrm{mM}$ in all samples.

The final $\mathrm{pH}$ was adjusted to $10.30 \pm 0.10$ so as to minimize the degradation of omeprazole and in some samples the $\mathrm{pH}$ was adjusted to 7.55 and 12.04 in order to study the influence of the $\mathrm{pH}$ in the omeprazole structural conformation. ${ }^{1} \mathrm{H}-\mathrm{NMR}$ variations in the chemical shifts $(\Delta \delta)$ were calculated according to $\Delta \delta=\delta$ (complex) $-\delta$ (free).

\section{Simulation details}

The Molecular Dynamics simulations were performed using the GROMACS package [12] and employing the GROMACS ffgmx force field [13]. 
The $\beta \mathrm{CD}$ structure was obtained from the HIC-Up on-line database [14]. The initial structure of the omeprazole molecule was also produced as a pdb file. The structures were then converted to GROMACS input files (conformation and topology) using PRODRG [15]. The deprotonated form of OME present in solutions with $\mathrm{pH}=10[16,17]$ was obtained by extracting the benzimidazole proton when running PRODRG and setting the partial charges on the molecule according to the charge distributions obtained from GAMESS [18] at the pm3 level, for the protonated and deprotonated forms. The minimized energy structures obtained from GAMESS and GROMACS in the gas phase for the protonated forms presented differences in bond length smaller than $0.05 \AA$.

In order to maintain the electroneutrality of the systems, one sodium ion was introduced. The long range electrostatic interactions were handled by particle-mesh ewald method [19]. The solvent was considered explicitly using the SPC water model and an algorithm for rigid water molecules [20]. The system was enclosed in a cell with an approximate volume of $33 \times 32 \times 32 \AA^{3}$ and with periodic boundary conditions. Each cell enclosed more than 1020 water molecules. The simulation was conducted in the NPT ensemble at a constant temperature of $300 \mathrm{~K}$ with coupling to an external bath [21].

An equilibration run of at least $0.5 \mathrm{~ns}$ was done previous to the production trajectory runs, using a timestep of $1 \mathrm{fs}$, without any constraints. The formation of the inclusion complex is a result of the equilibration process and equilibration was only considered to be completed upon inclusion. The production runs were carried for $30 \mathrm{~ns}$ with a timestep of $2.0 \mathrm{ps}$.

\section{Results and discussion}

\section{NMR spectroscopy}

One of the problems in obtaining a stable pharmaceutical formulation with omeprazole is the fact that it degrades very rapidly at acidic or neutral $\mathrm{pH}$ values. At $\mathrm{pH}=10$ the molecule is in the deprotonated form, presenting a better stability and larger solubility. The ${ }^{1} \mathrm{H}-\mathrm{NMR}$ spectra at $25{ }^{\circ} \mathrm{C}$ and $\mathrm{pH}=10.30 \pm 0.10$ of free omeprazole, omeprazole complexed with $\beta \mathrm{CD}$ and with $\mathrm{M} \beta \mathrm{CD}$ are shown in Fig. 2a-c, respectively.

The expansion of the ${ }^{1} \mathrm{H}-\mathrm{NMR}$ spectrum of the molecule in the region of the methoxy (aii) and methyl (bii) groups at $\mathrm{pH}=10.30^{\circ} \mathrm{C}$ and $25^{\circ} \mathrm{C}$, revealed that the peaks attributed to these groups were "split", as shown in Fig. 3, with the appearance of a smaller peak at slightly smaller $\delta$ values for each resonance. These small peaks were not detectable at $\mathrm{pH}=7.55$, and at $\mathrm{pH}=12.04$ appear at the left side of the large peak. At $\mathrm{pH}=12.04$, these smaller

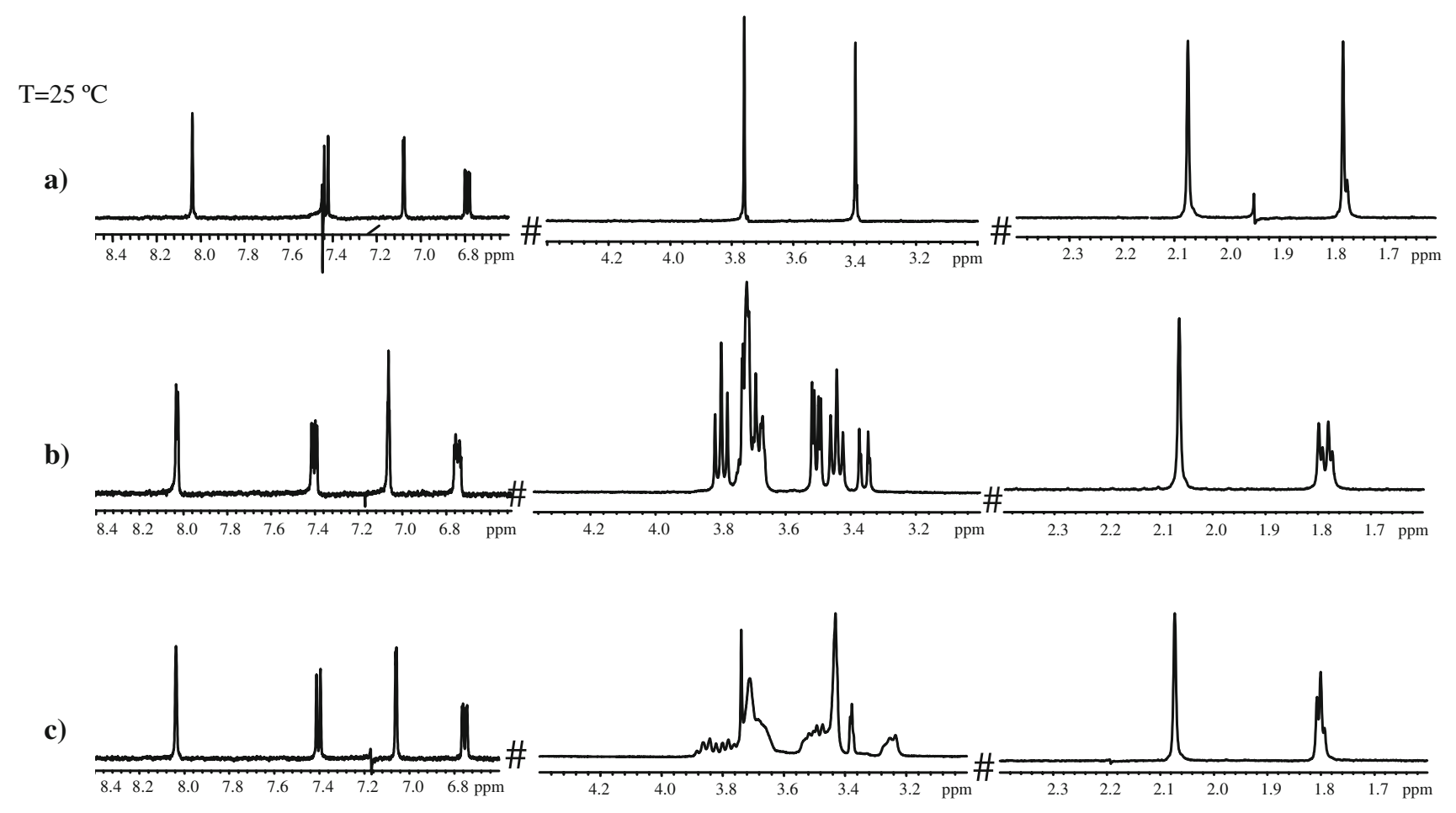

Fig. $2{ }^{1} \mathrm{H}-\mathrm{NMR}$ spectra of free $\mathrm{OME}(\mathbf{a})$; OME complexed with $\beta \mathrm{CD}(\mathbf{b})$; and with $\mathrm{M} \beta \mathrm{CD}(\mathbf{c})$ at $25^{\circ} \mathrm{C}$ and $\mathrm{pH}=10.30 \pm 0.10$ 

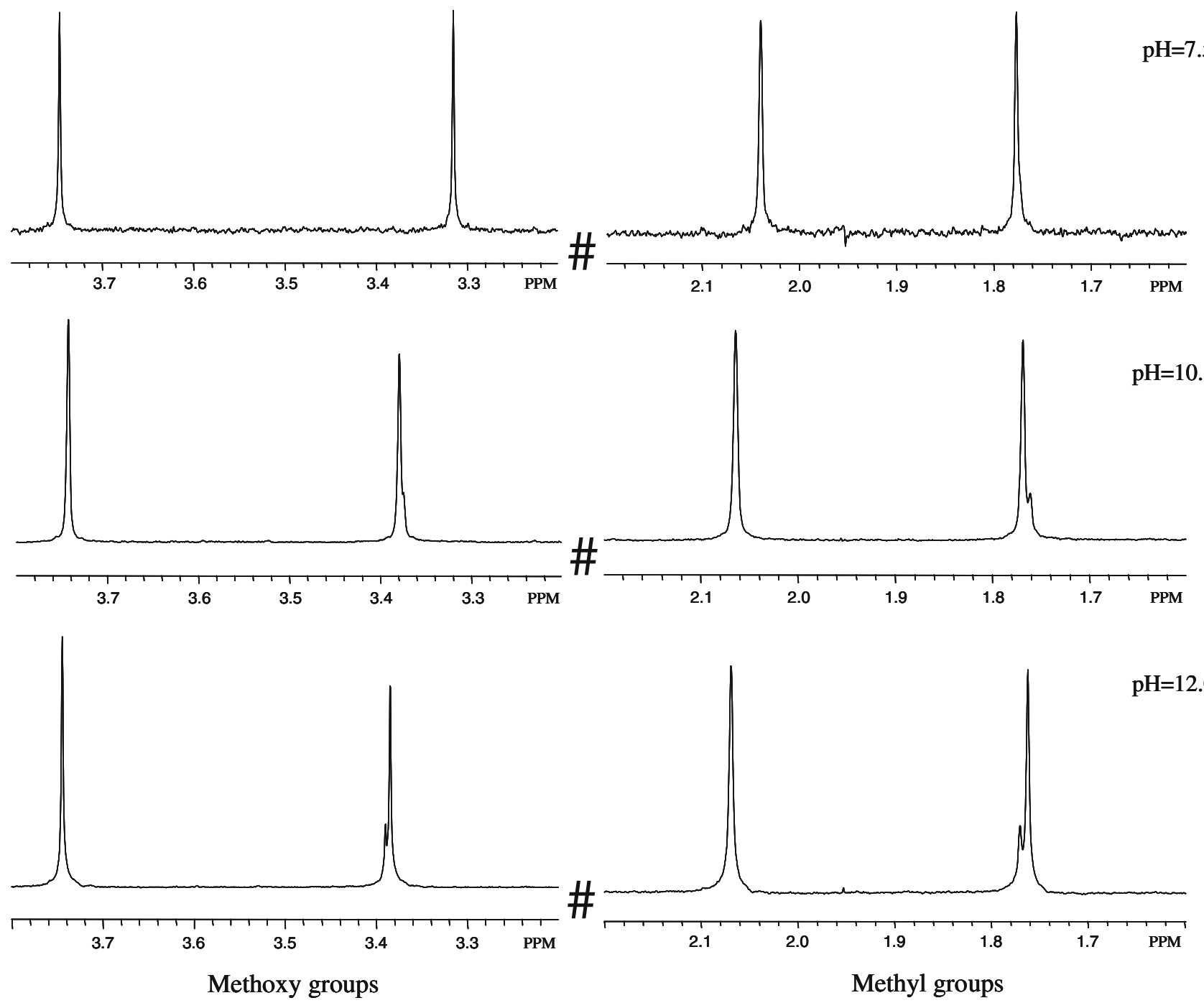

Fig. 3 Expansion of the ${ }^{1}$ H-NMR spectrum of free OME for the regions of methoxy [(ai) and (aii)] and methyl groups [(bi) and (bii)] at different $\mathrm{pHs}$ at $25^{\circ} \mathrm{C}$

peaks present a larger relative area $(\sim 25 \%)$ compared to the relative area of the same peak visible at $\mathrm{pH}=10.30$ ( $\sim 10 \%)$. It should also be noted that the effect is identical in both sets of protons, located at different ends of the molecule. This behaviour may be explained by a dependence of the conformational stability on the $\mathrm{pH}$ as observed for other molecules [22]. The difference in the values of $\delta$ for the large and smaller peaks at $\mathrm{pH}=10.30$ is probably related to aromatic electronic ring currents caused by opposite ring effects, which at some metastable conformation may deprotect the above mentioned protons. By changing the $\mathrm{pH}$, another metastable conformation is favoured, in this case having a protecting effect. At $\mathrm{pH}=10.30$, the relative area and $\delta$ of the peaks attributed to the protons in the methyl (bii) group vary with temperature, as described in Table 1.
Table 1 Chemical shifts and relative signal areas for peak 1 and peak 2 at $\mathrm{pH}=10.30$ as function of temperature

\begin{tabular}{llll}
\hline $\begin{array}{l}\text { Temperature } \\
\left({ }^{\circ} \mathrm{C}\right)\end{array}$ & $\begin{array}{l}\text { Chemical shifts } \\
1(\mathrm{ppm})\end{array}$ & $\begin{array}{l}\text { Chemical shifts } \\
2(\mathrm{ppm})\end{array}$ & $\begin{array}{l}\text { Signal relative } \\
\text { ratio }(\%)^{*}\end{array}$ \\
\hline 25 & 1.764 & 1.756 & 19 \\
35 & 1.901 & 1.893 & 22 \\
50 & 2.083 & 2.076 & 34 \\
\hline
\end{tabular}

* Relative signal area $=($ peak area 2$) /($ peak area $2+$ peak area 1$)$

When the temperature is increased from $25{ }^{\circ} \mathrm{C}$ to $50{ }^{\circ} \mathrm{C}$, the $\delta$ for the largest peak of the methyl group (bii) increases from $\delta=1.764-2.083 \mathrm{ppm}$, with a similar change in the $\delta$ of the smaller peak, and the signal relative ratio of the smaller peak increases steadily from $19 \%$ at $25{ }^{\circ} \mathrm{C}$ to $22 \%$ at $35{ }^{\circ} \mathrm{C}$ and to $34 \%$ at $50{ }^{\circ} \mathrm{C}$. These 

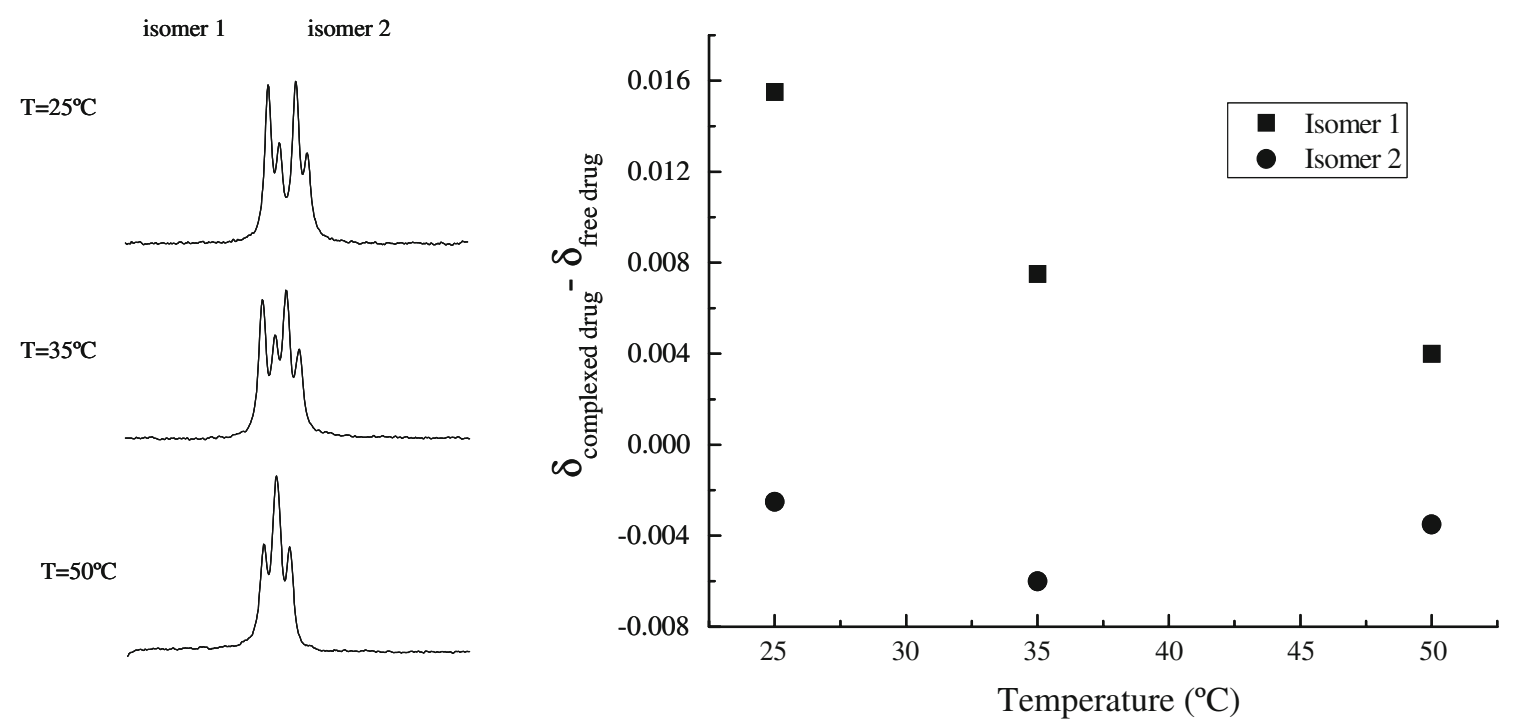

Fig. 4 Expansion of the ${ }^{1} \mathrm{H}-\mathrm{NMR}$ spectra and $\Delta \delta$ for the methyl group [(bii)] of OME complexed with $\beta \mathrm{CD}$ as a function of temperature, $\mathrm{pH}=10.30 \pm 0.10$

alterations are consistent with a very dynamic behaviour of the drug, since the alterations in both chemical shifts and ratios of conformers imply a significant alteration in conformation.

Figure 4 shows the expansion of the ${ }^{1} \mathrm{H}-\mathrm{NMR}$ spectrum and the $\delta$ of complexed omeprazole with $\beta \mathrm{CD}$ in the region of the methyl group (bii). This figure shows, at $25^{\circ} \mathrm{C}$, the appearance of two sets of two peaks, each in the region of the methyl group (bii). Each of these sets is very similar to the respective protons in the absence of cyclodextrin. The relative area of the small peak in each set $(\sim 31 \%)$ is, however, quite different from the corresponding areas in the absence of cyclodextrin at $25^{\circ} \mathrm{C}(\sim 10 \%)$. The separation between the two sets indicates the separation between two different populations, which tend to merge as the temperature is increased. At $50{ }^{\circ} \mathrm{C}$ a significant superposition of the resonances occurs.

\section{Molecular Dynamics simulation}

Molecular Dynamics studies of the inclusion of the isomers into the cyclodextrin cavity show that there is a slightly deeper inclusion of the $R$ isomer inside the cavity, as visible in Fig. 5.

At the same time, it was observed that the $S$ isomer retains a larger conformational freedom when included in the cavity. This is visible in the larger dispersion of values in the distribution of distances between the oxygens in groups (aii) to the hydrogens on the positions 2 and 3 of the cyclodextrin rings, as presented in Fig. 6.

The different $\delta$ values observed for the two sets of peaks may therefore be explained by the different proximity between the methoxy (bii) group and the oxygens in

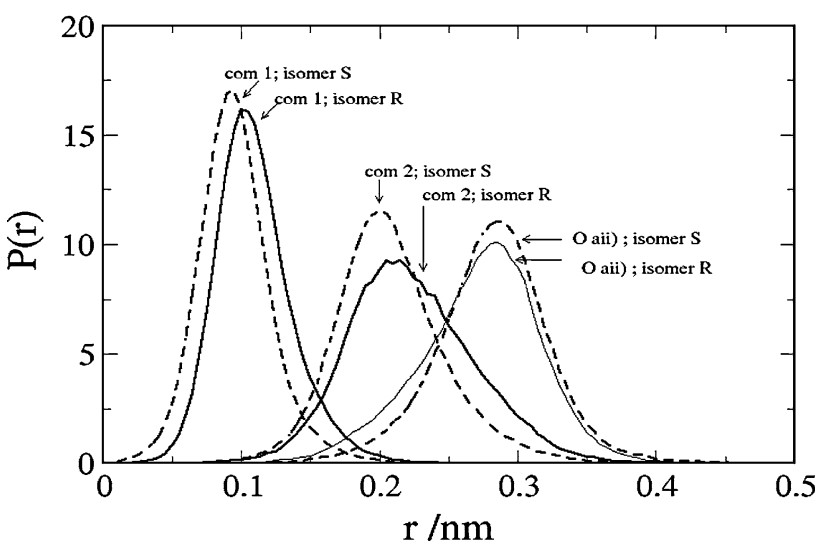

Fig. 5 Distribution of distances for the oxygen in group (aii) and the center of mass of each of the benzimidazole rings (com1 denotes the center of mass of the "imidazole" part and com2 that of the "benzene" ring) to the center of mass of the group formed by $\mathrm{O} 4$ of the cyclodextrin. Full line and dashed line correspond to isomers $R$ and $S$ respectively

positions 2 and 3 in the wider side of the cyclodextrin cavity, as shown in Fig. 7. The separation of these sets of peaks in the presence of the cyclodextrin thus results from the action of the latter as a chiral selector. In this view, each set of peaks may be attributed to a specific isomer. Previous work [9] has shown that the $S$ isomer forms less stable complexes with cyclodextrin, in accordance with our observation that this isomer is less deeply included in the cavity. The assignment of the peaks can also be done resorting to the molecular dynamics results. The results presented in Fig. 7 show that there is a significant difference in the proximity between the hydrogens in the OME and the oxygens in the wider entrance of the cyclodextrin, which may have a counterpart in the protection/ 


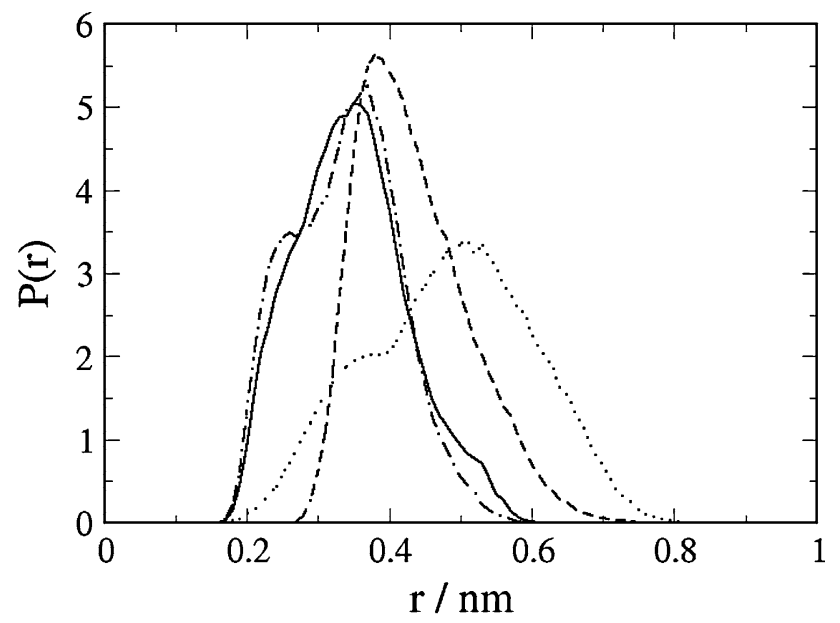

Fig. 6 Distribution of nearest-neighbor distance for the oxygen atom (aii) to the hydrogen atoms in position 6 (full and dotted lines for isomer $R$ and $S$ respectively) and O (ai) to the hydrogens in positions 2 and 3 (dash-dotted and dotted lines for isomers $R$ and $S$ respectively) for both isomers when included in the cavity

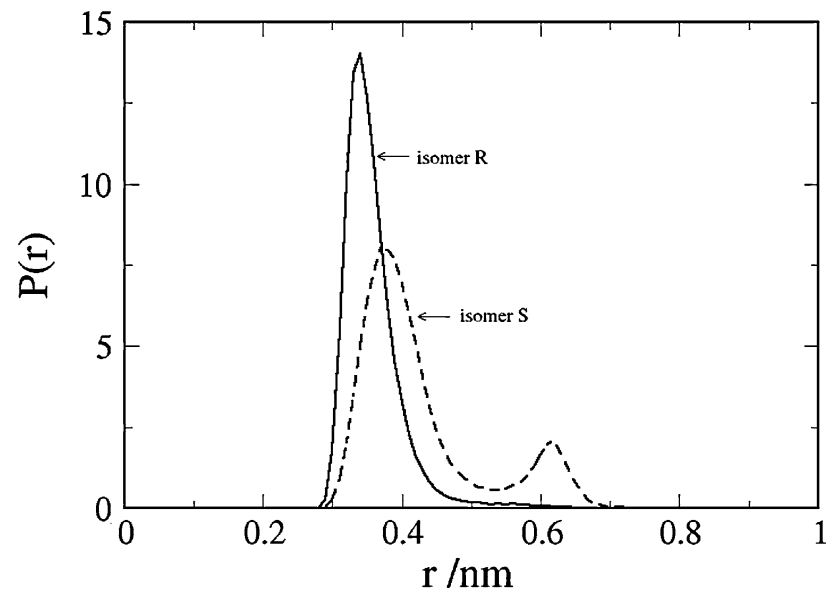

Fig. 7 Nearest-neighbor distances from the carbon in methoxy (bii) to the oxygen atoms in position 2 and 3 of the cyclodextrin. Full line and dashed line correspond to isomers $R$ and $S$ respectively

deprotection of the former. Following this reasoning, the set with larger $\delta$ can be attributed to isomer $R$. The tendency for overlap between the two sets of peaks as temperature increases can be explained by an increased conformational freedom of the two molecules that results in a less specific interaction.

In the case of the drug complexed with $\mathrm{M} \beta \mathrm{CD}$, the methylated derivative, the enantiomeric separation is less marked and with increasing temperature the two enantiomers become almost indistinguishable. We suggest that this observation results from the formation of a more stable inclusion complex between this cyclodextrin and each of the drug enantiomers [23], and that with increasing temperature existing differences in binding constants tend to disappear (smaller $\Delta \delta$ ).
The results observed indicate that in the presence of cyclodextrin the drug shows enantioselectivity because $\beta \mathrm{CD}$ acts as a chiral selector. However, this fact is not so clearly observed in the presence of $\mathrm{M} \beta \mathrm{CD}$, probably because in this case the inclusion of both enantiomers in the cyclodextrin cavity is deeper [23].

\section{Conclusion}

This work allows concluding that the combined use of NMR spectroscopy and molecular dynamics simulation constitutes a clear, simple, and easy methodology to analyse the occurrence of chiral selectivity for drugs, in this case OME, in presence of natural and derivative cyclodextrins, $\beta \mathrm{CD}$ and $\mathrm{M} \beta \mathrm{CD}$. The characteristic features in the spectra have been rationalised resorting to information provided by the Molecular Dynamics simulations, indicating that OME $(R)$-isomer is preferentially included in the $\beta \mathrm{CD}$ cavity, acting this cyclodextrin as a chiral selector for this compound. The same was not observed in the presence of $\mathrm{M} \beta \mathrm{CD}$, because with this cyclodextrin the inclusion of the drug in the cavity is deeper, and this fact hampers the use of this cyclodextrin as a chiral selector in the case of OME.

Acknowledgments This work was financially supported by $\mathrm{PhD}$ grants SFRH/BD/19175/2004 and SFRH/BD/17440/2004 and research grant POCI/SAU-OBS/55802/2004 from FCT (Fundação para a Ciência e a Tecnologia, Portugal). The authors would like to thank Belmac Laboratory, S.A. (Madrid, Spain) for kindly donating omeprazole and Roquette (Lestrem, France) for their support providing $\beta \mathrm{CD}$ and $\mathrm{M} \beta \mathrm{CD}$.

\section{References}

1. Lee, D.Y., Shin, H.S., Bae, S.K., Lee, M.G.: Effects of enzyme inducers and inhibitors on the pharmacokinetics of intravenous omeprazole in rats. Biopharm. Drug Dispos. 27, 209-218 (2006). doi:10.1002/bdd.502

2. Howden, C.W.: Clinical pharmacology of omeprazole. Clin. Pharmacokinet. 20, 38-40 (1990). doi:10.2165/00003088-1991 20010-00003

3. Sarisuta, N., Tourtip, T., Chuarcharoern, S.: Chemical stability and mechanism of degradation of omeprazole. Thai. J. Pharm. Sci. 22, 81-88 (1998)

4. Sinha, V.R., Anitha, R., Ghosh, S., Nanda, A., Kumria, R.: Complexation of celecoxib with $\beta$-cyclodextrin: characterization of the interaction in solution and in solid state. J. Pharm. Sci. 94, 676-687 (2005). doi:10.1002/jps.20287

5. Anselmi, C., Centini, M., Ricci, M., Buonocore, A., Granata, P., Tsuno, T., et al.: Analytical characterization of a ferulic acid $/ \gamma$ cyclodextrin inclusion complex. J. Pharm. Biomed. Anal. 40, 875-881 (2006). doi:10.1016/j.jpba.2005.08.019

6. Yap, K.L., Liu, X., Thenmozhiyal, J.C., Ho, P.C.: Characterization of the 13-cis-retinoic acid/cyclodextrin inclusion complexes by phase solubility, photostability, physicochemical and computational analysis. Eur. J. Pharm. Sci. 25, 49-56 (2005). doi: 10.1016/j.ejps.2005.01.021 
7. Can, Q.B., Lima, V.V., Oliveira, R.V., Cassiano, N.M., Degani, A.L.G., Pedrazzoli Jr., J.: Enantiomeric determination of the plasma levels of omeprazole by direct plasma injection using high-performance liquid chromatography with achiral-chiral column-switching. J. Chromat. B. 798, 275-281 (2003). doi: 10.1016/j.jchromb.2003.09.053

8. Orlando, R.M., Bonato, P.S.: Simple and efficient method for enantioselective determination of omeprazole in human plasma. J. Chromat. B. 795, 227-235 (2003). doi:10.1016/S1570-0232 (03)00570-1

9. Nevado, J.J.B., Peñalvo, G.C., Dorado, R.M.R.: Method development and validation for the separation and determination of omeprazole enantiomers in pharmaceutical preparations by capillary electrophoresis. Anal. Chim. Acta 533, 127-133 (2005). doi:10.1016/j.aca.2004.11.018

10. Bonato, P.S., Paias, F.O.: Enantioselective analysis of omeprazole in pharmaceutical formulations by chiral high-performance liquid chromatography and capillary electrophoresis. J. Braz. Chem. Soc. 15, 318-323 (2004). doi:10.1590/S0103-50532004 000200025

11. Ribeiro, L., Carvalho, R.A., Ferreira, D.C., Veiga, F.J.B.: Multicomponent complex formation between vinpocetine, cyclodextrins, tartaric acid and water-soluble polymers monitored by NMR and solubility studies. Eur. J. Pharm. Sci. 24, 1-13 (2005). doi:10.1016/j.ejps.2004.09.003

12. Lindahl, E., Hess, B., van der Spoel, D.: GROMACS 3.0: a package for molecular simulation and trajectory analysis. J. Mol. Model 7, 306-317 (2001)

13. Berendsen, H.J.C., van der Spoel, D., van Drunen, R.: GROMACS: a message-passing parallel molecular dynamics implementation. Comput. Phys. Commun. 91, 43-56 (1995). doi: 10.1016/0010-4655(95)00042-E

14. Kleywegt, G.J., Jones, T.A.: Databases in protein crystallography. Acta Crystallogr. D Biol. Crystallogr. D54, 1119-1131 (1998)
15. Schuettelkopf, A.W., van Aalten, D.M.F.: PRODRG-a tool for high throughput crystallography of protein-ligand complexes. Acta Crystallogr. D Biol. Crystallogr. D6, 1355-1363 (2006)

16. Brändström, A., Bergman, N.A., Grundevik, I., Johansson, S.L., Tekenbergs-Hjelte, L., Ohlson, K.: Chemical reactions of omeprazole and omeprazole analogues. III. Protolytic behaviour of compounds in the omeprazole system. Acta Chem. Scand. 43, 569-576 (1989)

17. Yang, R., Zavala, S.G., Schulman, P.J.: Acid-base chemistry of omeprazole in aqueous solutions. Anal. Chim. Acta 481, 155-164 (2003). doi:10.1016/S0003-2670(03)00076-X

18. Schmidt, M.W., Baldridge, K.K., Boatz, J.A., Elbert, S.T., Gordon, M.S., Jensen, J.H., et al.: General atomic and molecular electronic-structure system. J. Comput. Chem. 14, 1347-1363 (1993). doi:10.1002/jcc.540141112

19. Essman, U., Perela, L., Berkowitz, M.L., Darden, T., Lee, H., Pedersen, L.G.: A smooth particle mesh ewald method. J. Chem. Phys. 103, 8577-8592 (1995). doi:10.1063/1.470117

20. Miyamoto, S., Kollman, P.A.: An analytical version of the shake and rattle algorithms for rigid water models. J. Comput. Chem. 13, 952-962 (1992). doi:10.1002/jcc.540130805

21. Berendsen, H.J.C., Postma, J.P.M., DiNola, A., Haak, J.R.: Molecular dynamics with coupling to an external bath. J. Chem. Phys. 81, 3684-3690 (1984). doi:10.1063/1.448118

22. Rozou, S., Voulgari, A., Antoniadou-Vyza, E.: The effect of $\mathrm{pH}$ dependent molecular conformation and dimerization phenomena of piroxicam on the drug: cyclodextrin complex stoichiometry and its chromatographic behaviour: a new specific HPLC method for piroxicam: cyclodextrin formulations. Eur. J. Pharm. Sci. 21, 661-669 (2004). doi:10.1016/j.ejps.2004.01.007

23. Figueiras, A., Sarraguça, J., Carvalho, R.A., Pais, A.A.C.C., Veiga, F.: Interaction of omeprazole with a methylated derivative of $\beta$-cyclodextrin: phase solubility, NMR spectroscopy and molecular simulation. Pharm. Res. 24, 377-390 (2007). doi: 10.1007/s11095-006-9161-8 